\section{AB1286 EVALUATION OF CARDIOVASCULAR RISK FACTORS AND PREVALENCE OF METABOLIC SYNDROME IN PATIENTSWITH DIAGNOSIS OF ANKYLOSING SPONDYLITIS:}

Severino Correia Do Prado Neto ${ }^{1}$, Érika Carvalho de Aquino ${ }^{2}$, Jozelia Rêgo ${ }^{1}$, Nílzio Da Silva ${ }^{1}$, Fabiana Pina ${ }^{1}{ }^{1}$ Hospital das Clínicas de Goiânia - Universidade Federal de Goiás, Goiânia, Brazil; ${ }^{2}$ Universidade Federal de Goiás, Goiânia, Brazil

Background: Cardiovascular events are the main causes of mortality in patients with Ankylosing Spondylitis. In addition, a higher prevalence of Metabolic Syndrome is reported in this group. With immunobiological therapy, much progress has been made in controlling the inflammatory process, but the cardiovascular risk remains high.

Objectives: To evaluate the prevalence of cardiovascular risk factors and Metabolic Syndrome in patients with Ankylosing Spondylitis at the Rheumatology Outpatient Clinic of HC-UFG and to correlate them with epidemiological, clinical, laboratory and radiographic characteristics of the disease.

Methods: Data from 59 patients were collected in medical records between July and August 2018. Clinical characteristics, cardiovascular risk factors and metabolic components were analyzed. Descriptive analyzes of the data were made, prevalences and their reasons were calculated. The associations between variables were assessed by chi-square test and Fisher's exact test.

Results: $81.4 \%$ were male, $67.8 \%$ self-denominated non-whites, average age 46.7 years. Isolated axial joint involvement was the most frequently observed (54.2\%). Enthesopathic lesions were identified in $30.51 \%$ of the cases. Uveitis had a higher prevalence (22.02\%), 4.2 times higher in the subgroup with HLA-B27 positive $(p=0.0002)$. HLA-B27 was present in $67.8 \%$. Advanced sacroilitis (grades 3 and 4 ) and syndesmophytosis were identified in $61.1 \%$ and $49.2 \%$, respectively, but didn't presented significant correlation with the presence of HLA-B27. $64,4 \%$ were using anti-TNF alone or in combination. The majority of the patients $(72.9 \%)$ were sedentary. Clinical comorbidities were reported in $66.1 \%$ of the cases, with dyslipidemia (45.8\%), systemic arterial hypertension (37.6\%) and diabetes mellitus $(13.6 \%)$ being the most common. Metabolic Syndrome was diagnosed in $23.7 \%$ of the samples. Normal levels of triglycerides and fasting glycemia and lower prevalence of Metabolic Syndrome had a statistically significant association with the presence of HLA-B27 ( $p=0.006 ; 0.026$ and 0.014, respectively). Patients with HLA-B27 present had $61 \%$ lower frequency of Metabolic Syndrome. There was no association between the syndrome and its components with anti-TNF therapy; BASDAI; BASFI; metric evaluation; uveitis; degree of sacroilitis and syndesmophytosis.

Conclusion: The prevalence of Metabolic Syndrome was below that is described in other populations. The presence of HLA-B27 was considered a protective factor for Metabolic Syndrome, triglyceride levels and fasting glycemia. This finding may be related to the presence of several HLAB27 alleles, usually non-subtyped, and to the great ethnic miscegenation of the Brazilian population. Our observation suggests that spondylitics should be routinely evaluated for cardiovascular risk factors.

\section{REFERENCES}

[1] Maia, DG, et al. Metabolic Syndrome in patients with ankylosing spondylitis receiving anti-TNF alfa therapy: association with predictors of cardiovascular risk. Clin Rheumatology 2011;36(10):2371-76.

[2] Fiorillo, MT, et al. CD8+ T-cell autoreactivity to an HLA-B27-restricted selfepitope correlates with ankylosing spondylitis. The Journal of Clinical Investigation 2000;106(1):47-53.

Disclosure of Interests: None declared

DOI: 10.1136/annrheumdis-2019-eular.6987

\section{AB1287 DISEASE EVOLUTION OF PRIMARY SJOGREN'S SYNDROME - A LONGITUDINAL STUDY}

Inês Rego de Fiqueiredo ${ }^{1}$, Jessica Tarn ${ }^{2}$, Dennis Lendrem ${ }^{2}$, Josephine Vila ${ }^{3}$, Elizabeth Kidd ${ }^{3}$, Julie Norris ${ }^{3}$, Ben Hargreaves ${ }^{3}$, Wan Fai Ng ${ }^{2,3}$. ${ }^{1}$ Unidade de Doenças Auto-imunes/Medicina 7.2, Hospital de Curry Cabral, Centro Hospitalar Universitário Lisboa Central (CHULC), Lisboa, Portugal; ${ }^{2}$ Musculoskeletal Research Group, Institute of Cellular Medicine, Newcastle University, NewcastleUpon-Tyne, United Kingdom; ${ }^{3}$ Newcastle-upon-Tyne Hospitals NHS Foundation Trust, Newcastle-Upon-Tyne, United Kingdom

Background: The natural history of primary Sjogren's syndrome (pSS) remains poorly understood. It has been suggested that the initial presentations may predict the course of disease (1), with gradual reduction of biological activity as measured by serum Immunoglobulins levels (2), while symptoms such as fatigue remaining stable over time(3).

Objectives: To evaluate how pSS progresses over time using ESSDAI (Eular Sjögren's Syndrome Disease Activity Index) and the ESSPRI (Eular Sjögren's Syndrome Patient Index), EQ5D-Time trade off (TTO) and Visual Analogue Scale (VAS) of health states.

Methods: Routine clinical data from a large single centre cohort in the UK were analysed on patients with $>3$ clinical visits, including up to the 10th visit. Outcomes (ESSDAI/ESSPRI and their component scores, EQ5D-3L and VAS) were analyzed by a random effects linear regression using STATA 14

Results: 346 patients out of 858 included, with a female preponderance of $89 \%$, and median age of 63 years. The median follow up time was 4.9 years, and median disease duration of 12 years. Anti-Ro was positive in $61 \%$ and anti-La in $42 \%$ of the patients.

ESSDAl score decreased 0.1 point per visit $(p=0.006)$. Anti-Ro and antiLa positive patients exhibiting a lower score $(p=0.012$ and 0.031$)$, and patients with MALT at presentation had a score up to 6 points higher $(p=0.002)$. Regarding the ESSDAl domains, the constitutional and hae matological domains showed increased activity ( $p$-value $<0.0001$ and 0.018), with Anti-Ro and/or Anti-La patients having higher scores ( $p$ $<0.0001$ and 0.001). In contrast, the glandular, articular and periphera nervous system domains showed decreases over time ( $p$-values 0.003 0.006 and $<0.0001$ )

ESSPRI score increased 0.05 point/visit $(p<0.0001)$. While Dryness scores remained relatively constant, Pain and Fatigue components of the ESSPRI increased over time (both $\mathrm{p}<0.0001)$. Dryness scores were higher in female patients $(p=0.04)$.

EQ5D-TTO worsened by 0.03 point/visit $(p<0.0001)$, but the VAS health states remained stable.

Conclusion: Our data suggest that symptoms of fatigue and pain as well as health utility worsen over time, whereas different ESSDAI domains showed different trends over time. Longer term follow-up to further understand the natural history of pSS is warranted.

\section{REFERENCES}

[1] Skopouli FN, Dafni U, loannidis JPA, Moutsopoulos HM. Clinical evolution, and morbidity and mortality of primary Sjogren's syndrome. Semin Arthritis Rheum. 2000;29(5):296-304.

[2] Pertovaara M, Pukkala E, Laippala P, Miettinen A, Pasternack A. A longitudinal cohort study of Finnish patients with primary Sjögren's syndrome: Clinical, immunological, and epidemiological aspects. Ann Rheum Dis. $2001 ; 60(5): 467-72$

[3] Haldorsen K, Bjelland I, Bolstad Al, Jonsson R, Gorgas Brun J. A five-year prospective study of fatigue in primary Sjögren's syndrome. Arthritis Res Ther. 2011;13.

Disclosure of Interests: None declared

DOI: 10.1136/annrheumdis-2019-eular.6189

\section{AB1288 PREVENTION OF VENOUS THROMBOEMBOLISM AND THE RISK OF POSTOPERATIVE COMPLICATIONS IN PATIENTS WITH RHEUMATOID ARTHRITIS AFTER TOTAL HIP ARTHROPLASTY:}

Alexey Rybnikov $^{1}$, Evgenij Bialik ${ }^{2}$, Tatiana Reshetnyak², Sergey Makarov ${ }^{2}$, Alexander Khramov ${ }^{2}$, Sergey Maglevaniy ${ }^{2} .{ }^{1}$ Nasonova Research Institute of Rheumatology, Moscow, Russian Federation; ${ }^{1}$ Nasonova Research Institute of Rheumatology, Moscow, Russian Federation

Background: According to the administrative data, confirmed by several meta-analyses, patients with rheumatoid arthritis (RA) in comparison with the General population shows an increased risk of venous thromboembolic complications more than twice. Drug prevention can reduce the risk of venous thromboembolism (VTE) in patients with rheumatic diseases. Objectives: The aim of this study was to analyze frequency of VTE, risk of bleeding and complications of the postoperative wound in patients with RA and osteoarthritis (OA) after total hip arthroplasty (THA).

Methods: Study included 486 patients (212 - with RA and 274 - with OA) who underwent primary THA. Each group of patients was divided into 3 subgroups by type of drug therapy (1-nadroparin calcium; 2-dabigatran etexilate; 3-nadroparin calcium with transfer to dabigatran etexilate). Intra-and postoperative blood loss and the wound healing process were assessed during the first 7 days after surgery.

Results: Postoperative VTE were reported in $36(7.4 \%)$ of 486 patients VTE in patients with RA were detected significantly less frequently than in $\mathrm{OA}(1.2 \%$ and $6.1 \%, \mathrm{p}=0.0013)$. Bleeding that required transfusion 
of blood in RA were found significantly more often than in OA (respectively $14.4 \%$ and $5.7 \%$ of cases; $P<0.001$ ). The number of cases requiring cancellation of anticoagulant therapy in patients with RA was significantly higher compared with the OA group $(6.6 \%$ and $1.4 \%$, respectively). Slow wound healing in RA was more common ( $n=56 ; 26.4 \%$ ) than in $\mathrm{OA}(\mathrm{n}=14 ; 5.1 \%)$. In patients who underwent monotherapy with calcium nadroparin VTE occurred more often than when using combination therapy $(p<0.0001)$ and more often than in the group of dabigatran etexilate $(p=0.054)$.

Conclusion: The frequency of VTE, the risk of bleeding and complications of postoperative wound in patients with RA and OA after THA were analyzed. So, our study determined the dependence of VTE complications and bleeding risk according to the patient's underlying nosology. Also the advantage of combined postoperative therapy over others was evaluated. Disclosure of Interests: None declared

DOI: 10.1136/annrheumdis-2019-eular.6996

\section{AB1289 TESTING DIFFERENT ITEMS INCLUDED IN THE DEFINITION OF REMISSION IN A MULTICENTRE SLE COHORT}

Francesca Saccon ${ }^{1}$, Margherita Zen ${ }^{1}$, Mariele Gatto ${ }^{1}$, Domenico Pe Margiotta ${ }^{2}$, Fulvia Ceccarelli $^{3}$, Giulia Frontini ${ }^{4}$, Gabriella Moroni ${ }^{4}$, Alessandra Bortoluzzi ${ }^{5}$, Marcello Govoni ${ }^{5}$, Viola Signorini ${ }^{6}$, Marta Mosca ${ }^{6}$, Francesca Dall'ara ${ }^{7}$, Angela Tincani ${ }^{7}$, Anna Chiara Frigo ${ }^{8}$, Antonella Afeltra ${ }^{2}$, Fabrizio Conti ${ }^{3}$, Andrea Doria'. ' 'University of Padova, Division of Rheumatology, Department of Medicine DIMED, Padova, Italy; ${ }^{2}$ Università Campus Bio-Medico di Roma, Unit of Allergy, Clinical immunology and Rheumatology, Roma, Italy, ${ }^{3}$ Sapienza University of Roma, Dipartimento di Medicina Interna e Specialità Mediche, Roma, Italy;

${ }^{4}$ Fondazione Ca' Granda IRCCS Ospedale Maggiore Policlinico Milano, Division of Nephrology, Milano, Italy; ${ }^{5}$ University of Ferrara and Azienda OspedalieroUniversitaria S. Anna, Dep. of Medical Sciences, Ferrara, Italy; ${ }^{6}$ University of Pisa, Rheumatology Unit, Dep. of Internal Medicine, Pisa, Italy, ${ }^{7}$ University of Brescia, Rheumatology and Clinical Immunology Unit Spedali Civili and Dep. of Clinical and Experimental Science, Brescia, Italy; ${ }^{8}$ University of Padova, Dep. of Cardiac-

Thoracic-Vascular Sciences and Public Health Biostatistics, Padova, Italy

Background: Remission is the most desirable target in the treatment systemic lupus erythematosus (SLE) however, a universally accepted definition of remission in SLE is still missing.

Objectives: To test the contribution of the different items included into the currently used definitions of remission in SLE.

Methods: We studied 646 Caucasian patients from a multicentre lupus cohort followed for at least 5-years: female 585 (90.6\%), mean age at baseline $40.59 \pm 12.14$ years, mean disease duration $9.18 \pm 6.86$ years. Disease activity was assessed by clinical SLE Disease Activity Index 2000 (CSLEDAI) and SELENA-SLEDAI physician global assessment (PGA), and damage by Systemic Lupus International Collaborating Clinics/ACR Damage Index (SDI). To test the performance of the different items included in the definitions of SLE remission [1, 2] we identify 7 subtypes of remission: (1) $P G A(0-3)<0.5$; (2) cSLEDAl $=0$; (3) prednisone (PDN) $\leq 5 \mathrm{mg} /$ day; (4) $P G A<0.5$ and $P D N \leq 5 m g / d a y ; ~(5) ~ c S L E D A l=0$ and $P G A<0.5$; (6) cSLEDAl $=0$ and $P D N \leq 5 \mathrm{mg} /$ day; (7) $c S L E D A l=0$ and $P D N \leq 5 \mathrm{mg} /$ day and $P G A<0.5$. The effect of remission on SDI was evaluated by Poisson regression analysis.

Results: The number of patients achieving remission according to the different definitions is show in Figure 1. The proportion of patients who maintained prolonged remission (5-consecutive years) was: $P G A<0.5$ 13.0\%; cSLEDAl=0 18.4\%; PDN $\leq 5 \mathrm{mg} /$ day $34.4 \%$; PGA $<0.5$ and $P D N \leq 5 \mathrm{mg} /$ day $12.5 \%$; cSLEDAl $=0$ and $P G A<0.512 .7 \%$; cSLEDAl $=0$ and $P D N \leq 5 \mathrm{mg} /$ day $16.6 \%$; CSLEDAl $=0$ and $P D N \leq 5 \mathrm{mg} /$ day and $P G A<0.512 .4 \%$.

Figure 1. Number of patients in remission according to the 3 single items

(prednisone $\leq 5 \mathrm{mg} /$ day; $\mathrm{PGA}<0.5 ; \mathrm{CSLEDAl}=0$ ) and their overlap during a follow-up period of 5 years for all the patients. A) Patients achieving at least 1-year remission. B) Patients achieving prolonged remission (5-consecutive years).
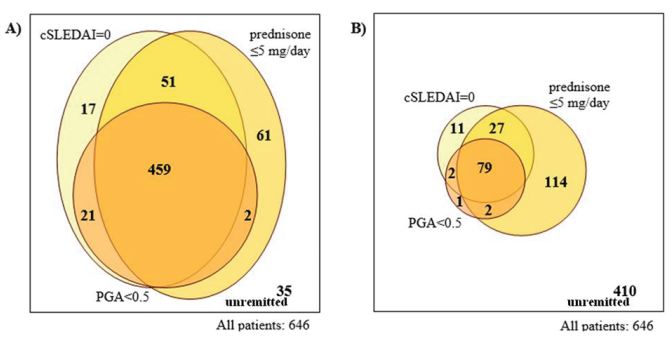

Table 1. Performance of 7 different remission subtypes in defining the risk of damage accrual (upper part) and the goodness-of-fit of the model (lower part).

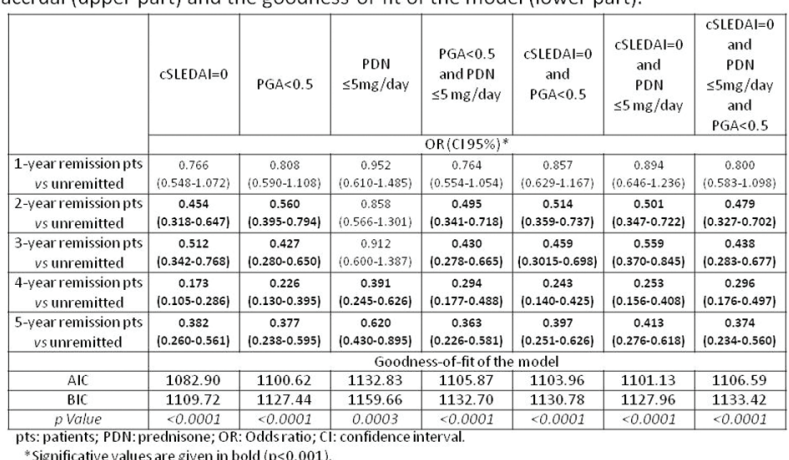

* Significative values are given in bold ( $\mathrm{p}<0.001$

Figure 1

When PGA $<0.5$ was added to CSLEDAI, $198(30.7 \%)$ patients lost 353 years in remission (1.8 years/patient): among them 195 (98.5\%) showed a $0.5 \leq P G A \leq 1$ suggesting a low disease activity state (LDA). When, $P G A<0.5$ was added to cSLEDAI $=0$ and $P D N \leq 5 \mathrm{mg} /$ day, $151(23.5 \%)$ patients lost 254 years in remission (1.7 years/patient): among them 149 $(98.0 \%)$ showed a $0.5 \leq P G A \leq 1$ suggesting again LDA. All remission subtypes were protective against damage $(p<0.001)$, however cSLEDAl=0 showed the best performance (lower AIC) (Table 1). At multivariate analysis all remission subtypes lasting $\geq 2$ consecutive years were protective against damage $(p<0.001)$, except $P D N \leq 5 \mathrm{mg} /$ day which was protective after 4 consecutive years.

Conclusion: The prevalence and extent of damage significantly decreased as the time spent in remission increased, irrespective of the remission subtype. The addition of $P G A<0.5$ to $c S L E D A l=0$ or to $c S L E D A l=0$ and $\mathrm{PDN} \leq 5 \mathrm{mg} /$ day results in a decrease in the time spent in remission without significant difference in damage accrual.

\section{REFERENCES}

[1] van Vollenhoven R, et al. 2014

[2] Zen M, et al. 2015

Disclosure of Interests: Francesca Saccon: None declared, Margherita Zen: None declared, Mariele Gatto: None declared, Domenico PE Margiotta: None declared, Fulvia Ceccarelli: None declared, Giulia Frontini: None declared, Gabriella Moroni: None declared, Alessandra Bortoluzzi: None declared, Marcello Govoni: None declared, Viola Signorini: None declared, Marta Mosca Paid instructor for: GlaxoSmithKline, Lilly, UCB, Francesca Dall'Ara: None declared, Angela Tincani Consultant for: UCB, Pfizer, Abbvie, BMS, Sanofi, Roche, GSK, AlphaSigma, Lilly, Jannsen, Cellgene, Novartis, Anna Chiara Frigo: None declared, Antonella Afeltra Grant/research support from: MSD, PFIZER, ABBVIE, ROCHE, UCB Speakers bureau: MSD, PFIZER, BMS, ROCHE, SANOFI, fabrizio conti: None declared, Andrea Doria: None declared

DOI: 10.1136/annrheumdis-2019-eular.4489

\section{AB1290 VITAMIN D AND PAIN SYNDROME IN BREAST CANCER PATIENTS TREATED WITH ADJUVANT LETROZOLE}

Stefania Sciacca, Nadia Melillo, Francesco Paolo Cantatore. University of Foggia Medical Area Departments, Department of Medical and Surgical Science, Foggia, Italy

Background: The third-generation aromatase inhibitors (Als) have shown a favorable overall risk-benefit profile in the upfront adjuvant therapy of postmenopausal estrogen receptor-positive breast cancer. Breast cancer patients treated with long term Als experience arthralgias and musculoskeletal aching often described as bone pain, musculoskeletal disorder, arthralgia.

Objectives: The purpose of this study was to investigate clinical, serological and anamnestic features associated to the joint pain syndrome in non-metastatic breast cancer patients treated with adjuvant Als.

Methods: Between June 2017 and December 2017 patients with early stage estrogen receptor-positive breast carcinomas treated with adjuvant letrozole, attending our Rheumatologic clinic to undergo osteoporosis screening, were included. Pre-existing symptoms and clinical, serological and imaging features were evaluated to assess the type of musculoskeletal disorder. 